\title{
DO ACESSO ESPACIAL À SAÚDE MENTAL: O CASO DO CAPS II DE BALNEÁRIO CAMBORIÚ-SC
}

VISBQP

UBERLÁNDIA 2019

\author{
CAMPOS, Rafael Alves de \\ Universidade do Vale do Itajaí, e-mail: arqrafaelcampos@gmail.com \\ JEFfE, Ana Paula Magalhães \\ Universidade do Vale do Itajaí, e-mail: arq3ana@gmail.com \\ LOCH, Márcia do Valle Pereira \\ Universidade do Vale do Itajaí, e-mail: marcia.loch@hotmail.com \\ MOLIN, Rodrigo Dal \\ Universidade do Vale do Itajaí, e-mail: rodrigodalmolin76@gmail.com \\ PELLIZZARO, Julia Perin, \\ Universidade do Vale do Itajaí, e-mail: juliaperin40@gmail.com \\ RIBEIRO, Raryana Fernanda, \\ Universidade do Vale do Itajaí, e-mail: raryanaribeirol@gmail.com \\ SESSEGOLO, Maria Eduarda Donatto, \\ Universidade do Vale do Itajaí, e-mail: raryanaribeirol@gmail.com
}

\begin{abstract}
RESUMO
Os Centros de Atenção Psicossociais (CAPS) são equipamentos destinados à promoção da saúde mental da população brasileira, mas para garantir isso à todos é essencial que suas instalações sejam espacialmente acessíveis. Visando atender a esta prerrogativa, o Grupo de Extensão Arquitetura e Cidades Saudáveis está desenvolvendo o projeto arquitetônico de adequação do CAPS II, na cidade de Balneário Camboriú - SC. Este artigo apresenta os resultados da primeira etapa da pesquisa que resultou em um diagnóstico preciso das condições espaciais do CAPS II. Para isso foi realizado uma avaliação pós-ocupação com foco na acessibilidade espacial, com abordagem quali-quantitativa, na qual foram aplicados levantamento de campo e documental, aplicação do Manual de Adaptação de Acessibilidade da Secretaria Especial dos Direitos da Pessoa com Deficiência do Ministério da Justiça e Cidadania (2016) e o processamento dos dados através de matriz de descobertas. Os resultados indicaram que 78\% dos aspectos avaliados estão em desacordo com a NBR9050/15. Com base nisso, foi possível elaborar uma matriz de recomendações com diretrizes de soluções projetuais para os conflitos existentes.
\end{abstract}

Palavras-chave: Avaliação Pós-ocupação, Acessibilidade, NBR9050/15, Centro de Atenção Psicossocial.

\begin{abstract}
The Psychosocial Care Centers are facilities aimed to promote mental health to brazilian population. But in order to be able to provide that service, it is necessary that its premises are spatially accessible. Aiming to meet that full spatial accessibility, the Extension Group "Arquitetura e Cidades Saudáveis" is developing an adequacy project in one of the Psychosocial Care Centers located in Balneário Camboriú - SC. This article presents the first part of the research that resulted in an diagnosis of the spatial conditions of the center. Aiming that, it was conducted a post-occupancy evaluation focused on accessibility, with a qualitative and quantitative approach, which was composed by a field survey, the appliance of the Accessibility Adaptation
\end{abstract}

CAMPOS, R. A.; JEFFE, A. P. M.; LOCH, M. V. P.; MOLIN, R. D.; PELLIZZARO, J. P.; RIBEIRO, R. F.; SESSEGOLO, M. E. D. Do acesso espacial à saúde mental: o caso do CAPS II de Balneário Camboriú-SC. In: SIMPÓSIO BRASILEIRO DE QUALIDADE DO PROJETO NO AMBIENTE CONSTRUÍDO, 6., 2019, Uberlândia. Anais... Uberlândia: PPGAU/FAUeD/UFU, 2019. p. 1195-1205. DOI https://doi.org/10.14393/sbqp19109. 
Manual from the Brazilian government and data process through the "Matriz de Descobertas" method. The results indicated that $78 \%$ of the analyzed items are not in conformity with the accessibility regulation, the NBR9050/15. From that, it was possible to elaborate a "Matriz de Recomendações", a recommendation matrix with projectual solutions guidelines to the current conflicts.

Keywords: Post-occupancy evaluation, Accessibility, NBR9050/15, Psychosocial Center Care.

\title{
1 INTRODUÇÃO
}

Os problemas de saúde mental ocupam mundialmente cinco posições no ranking das dez principais causas de incapacidade. No Brasil, 23 milhões de pessoas, que representam $12 \%$ da população, necessitam de algum tipo de atendimento nesta categoria (OMS, 2017). Desde a reforma psiquiátrica a rede de apoio e os atendimentos realizados atualmente tem 0 formato humanizado.

O movimento que deu origem a reforma psiquiátrica propunha mudanças no modelo de atenção e gestão nas práticas de saúde, na defesa da saúde coletiva, na equidade na oferta dos serviços, e no protagonismo dos trabalhadores e usuários dos serviços de saúde (MINISTÉRIO DA SAÚDE, 2005). O surgimento do movimento se deu em resposta à violência asilar e considera-se maior do que uma mudança na legislação. Segundo o Ministério da Saúde (2005, p.6), a reforma foi um

\begin{abstract}
processo político e social complexo, composto de atores, instituições e forças de diferentes origens, e que incide em territórios diversos, nos governos federal, estadual e municipal, nas universidades, no mercado dos serviços de saúde, nos conselhos profissionais, nas associações de pessoas com transtornos mentais e de seus familiares, nos movimentos sociais, e nos territórios do imaginário social e da opinião pública.
\end{abstract}

Com esta nova abordagem, começam a surgir equipamentos de saúde com uma assistência revisitada porém, é apenas em 2001, com a Lei Paulo Delgado (10.216/2001) que se direciona totalmente a legislação e normas sobre a assistência em saúde mental. Esta lei privilegia o oferecimento de tratamento em serviços de base comunitária e dispõe sobre a proteção e os direitos das pessoas com transtornos mentais (MINISTÉRIO DA SAÚDE, 2005).

A partir dessa nova abordagem das políticas de saúde mental, cria-se uma rede de equipamentos públicos de atendimento com diferentes abordagens. Dentro desta rede, há os Centros de Atenção Psicossocial (CAPS) cujo objetivo é oferecer atendimento e acompanhamento clínico, privilegiando a autonomia e a reabilitação social dos usuários, por meio do trabalho, lazer, exercício dos direitos civis e cidadania e o fortalecimento dos laços familiares e comunitários.

O CAPS, assim como todos os edifícios de uso público, deve obrigatoriamente obedecer às leis e normas de acessibilidade espacial segundo o decreto $5.296 / 2004$. O artigo quinto deste decreto coloca que "os órgãos da administração pública direta, indireta e fundacional [...] deverão dispensar atendimento prioritário às pessoas portadoras de deficiência ou com mobilidade reduzida". Acessibilidade espacial segundo a NBR 9050/2015 é a: 
possibilidade e condição de alcance, percepção e entendimento para utilização, com segurança e autonomia, de espaços, mobiliários, equipamentos urbanos, edificações, transportes, informação e comunicação, inclusive seus sistemas e tecnologias, bem como outros serviços e instalações abertos ao público, de uso público ou privado de uso coletivo, tanto na zona urbana como na rural, por pessoa com deficiência ou mobilidade reduzida (ABNT, 2015, p. 2).

Contudo, ainda segundo as autoras Bins Ely e Dischinger (2002), a acessibilidade é mais do que uma condição física de atingir um local desejado, é necessário permitir a orientação espacial e a comunicação entre as pessoas. Pinto (2017) também afirma que o espaço deve promover a acessibilidade como uma possibilidade do indivíduo ter acesso ao ambiente e/ou equipamento e propõe uma perspectiva de acessibilidade que agrupe a inclusão social e a cidadania, assim como Cohen, Duarte e Brasileiro (2012, p. VII) que afirmam que "há a dimensão política da acessibilidade estreitamente relacionada ao exercício da cidadania".

Portanto garantir as condições de acesso do CAPS é também garantir o acesso à inclusão social para pessoas que são muitas vezes colocadas à margem da sociedade, devido a suas condições de sofrimento psicológico. Quando o ambiente do CAPS não permite o acesso igualitário a todos, ele nega que pessoas possam exercer seus direitos de cidadãos.

Tendo em vista a necessidade de atender a pluralidade dos usuários, familiares e colaboradores de um equipamento de saúde como o CAPS, a Secretaria de Saúde do município de Balneário Camboriú buscou o Grupo de Extensão Arquitetura e Cidades Saudáveis e o curso de Arquitetura e Urbanismo da UNIVALI com pedido de auxílio para o desenvolvimento de projetos de humanização para o CAPS II.

Para atender a esse objetivo, através de uma abordagem quali-quantitativa, foi realizada uma Avaliação Pós Ocupação (APO). Esta avaliação é um instrumento de controle de qualidade do ambiente construído no decorrer do uso e de seu processo de produção, levando em consideração a percepção dos avaliadores, projetistas e dos usuários, sem minimizar a importância da avaliação do desempenho físico (ABIKO; ORNSTEIN, 2002; ROMERO; ORNSTEIN, 2003).

No presente artigo será relatado a avaliação deste equipamento público de saúde através de uma APO com foco na análise das condições de acessibilidade espacial do edifício tomando como base a NBR 9050/2015. Partindo destes conceitos, a próxima etapa do artigo relatará sobre as etapas de avaliação, seguidas dos resultados e conclusões elaboradas pelo Grupo de Extensão Arquitetura e Cidades Saudáveis.

\section{METODOLOGIA}

Uma vez colocado a importância do CAPS II como elemento da rede de apoio à promoção da saúde mental, buscou-se entender seu funcionamento diário, realizando levantamentos primários sobre a edificação a qual o mesmo está instalado, sobre os dados de registro documental e plantas baixas originais. Para melhor entendimento sobre a percepção dos usuários foram 
realizadas entrevistas buscando verificar a satisfação dos familiares e colaboradores a respeito do CAPS. Também foi realizada coleta de dados in loco como registro documental e fotográfico, levantamento do espaço físico e confecção do projeto as-built da edificação a partir de uma APO.

Para análise das condições de acessibilidade no CAPS II, usou-se uma metodologia de caráter quali-quantitativo exploratória com o auxílio de um check list de acessibilidade que faz parte do Manual de Aplicação do Ministério da Justiça e Cidadania, disponibilizado pela Secretaria Especial dos Direitos da Pessoa com Deficiência do Governo Federal. Esta aplicação da planilha ocorreu primeiramente in loco, com preenchimento da ferramenta à mão e depois digitalização e processamento dos dados.

O check list em questão sintetiza os itens da NBR 9050/15 para verificação das características espaciais de ambientes através da classificação de cada item como "ATENDE" - significando que o espaço analisado está de acordo com a norma -, "NÃO ATENDE" - significando que o ambiente não atende à norma e necessita de projeto -, e, por último, "NÃO SE APLICA" - assinalado quando não existe e não se faz necessário este tipo de elemento no projeto. No caso dos itens assinalados "NÃO ATENDE", há uma lacuna que pode ser preenchida especificando a razão da inadequação e qual ou quais os projetos necessários para adequação. Por fim existe um espaço para ser preenchido com recomendações indicadas pelo aplicador quanto à necessidade de projeto para adequação à norma (ver Figura 1).

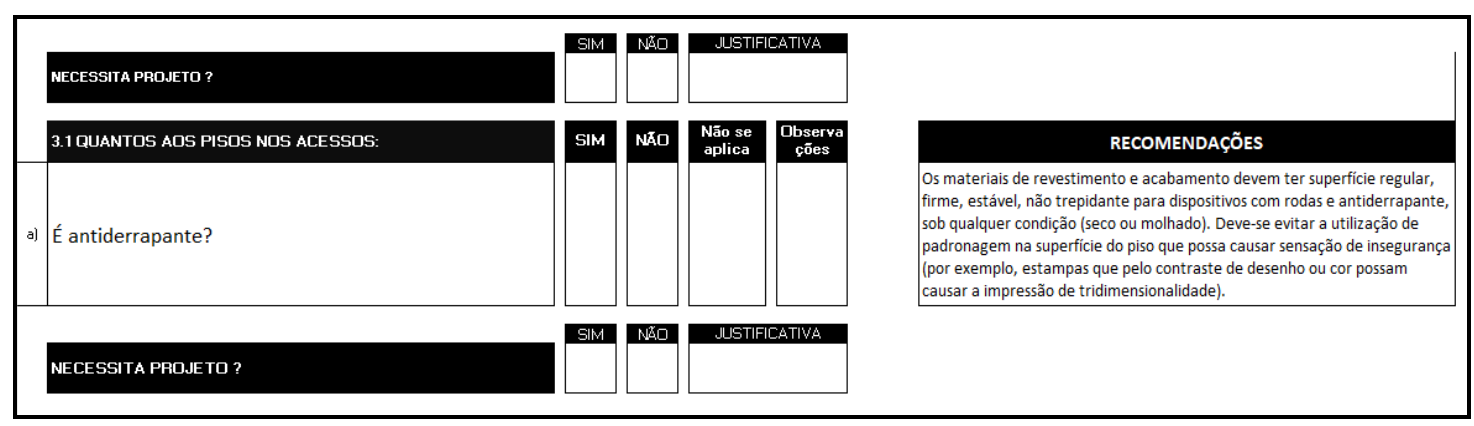

Figura 1 - Exemplo de item da planilha -

Fonte: Adaptado da SDPD (2018)

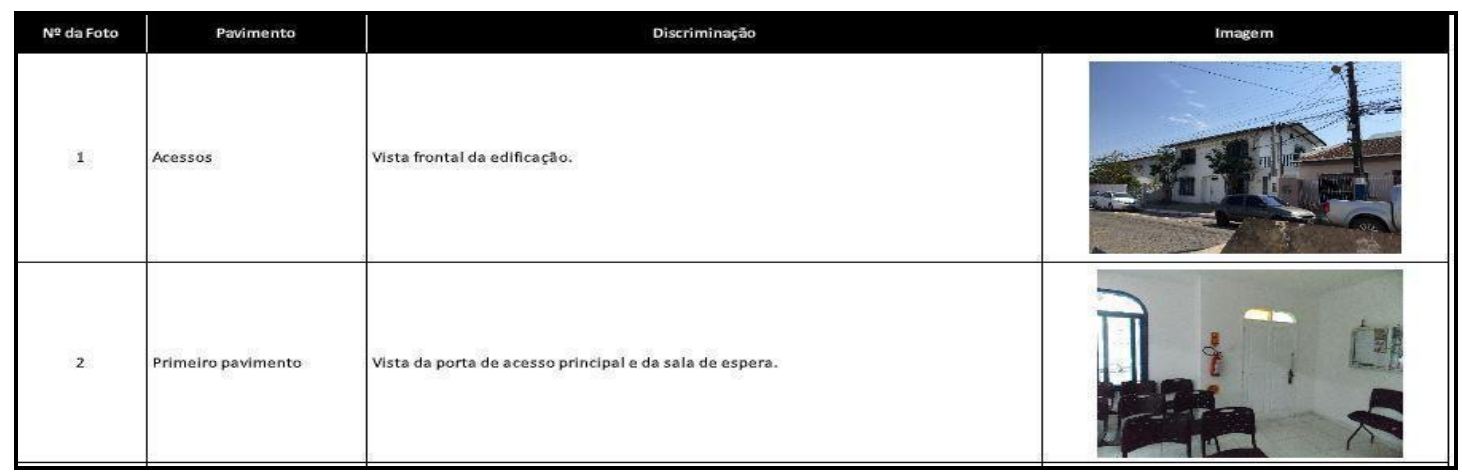

Figura 2 - Anexo fotográfico da planilha -

Fonte: Adaptado da SDPD (2018)

A etapa in loco para o preenchimento manual da tabela assim como levantamentos fotográficos e espaciais, demorou-se, em média, 5 horas. Após esta etapa, agruparam-se os dados coletados e o check list a fim de preencher a tabela no computador e também rever os quesitos que não 
haviam sido sanados na primeira etapa (ver Figura 2). Esta etapa de transposição dos dados coletados à tabela computadorizada também levou, em média, 5 horas.

Tabela 1 - Atendimento à norma por categoria

\begin{tabular}{|l|c|c|}
\hline \multicolumn{1}{|c|}{ Categoria } & Atende & Não atende \\
\hline 1_INFORMAÇÕES E OUTROS & 18 & 28 \\
\hline 3.2_ENTRADAS & 5 & 18 \\
\hline 4.1_CIRCULAÇÃO & 4 & 12 \\
\hline 4.2.1_RAMPAS & 2 & 48 \\
\hline 4.2.2_ESCADAS & 4 & 17 \\
\hline 5_ESQUADRIAS & 6 & 22 \\
\hline 6_SANITÁRIO ACESSÍVEL & 23 & 53 \\
\hline 7.2_BALCÕES & 2 & 10 \\
\hline 7.3_ASSENTOS & 0 & 4 \\
\hline 7.5_INTERIORES & 6 & 18 \\
\hline 11_RESTAURANTES E COPAS & 6 & 3 \\
\hline 12 a 14_ILUMINAÇÃO E SINALIZAÇÃO & 3 & 16 \\
\hline
\end{tabular}

Fonte: Autores (2018)

Tabela 2 - Comparação da hierarquia do check list com a percepção dos usuários

\begin{tabular}{|c|c|c|}
\hline Itens & Hierarquia do check list & Hierarquia do responsável técnico \\
\hline 3.2_ENTRADAS & $4^{\circ}$ & \multirow{3}{*}{$1^{\circ}$} \\
\hline 4.1_CIRCULAÇÃO & $8^{\circ}$ & \\
\hline 4.2.1_RAMPAS & $2^{\circ}$ & \\
\hline 4.2.2_ESCADAS & $6^{\circ}$ & $4^{\circ}$ \\
\hline 5_ESQUADRIAS & $3^{\circ}$ & $6^{\circ}$ \\
\hline 6_SANITÁRIO ACESSÍVEL & $1^{\circ}$ & $3^{\circ}$ \\
\hline 7.2_BALCÕES & $9^{\circ}$ & \multirow{4}{*}{$5^{\circ}$} \\
\hline 7.3_ASSENTOS & $10^{\circ}$ & \\
\hline 7.5 INTERIORES & $5^{\circ}$ & \\
\hline 11_RESTAURANTES E COPAS & $11^{\circ}$ & \\
\hline $\begin{array}{l}12 \text { a } 14 \text { ILUMINAÇÃO E } \\
\text { SINALIZAÇÃO }\end{array}$ & $7^{\circ}$ & $2^{\circ}$ \\
\hline
\end{tabular}

Fonte: Autores (2018)

A aplicação do check list permitiu uma visualização ampla dos principais conflitos existentes no espaço físico do CAPS II. Contudo, a planilha não gera 
uma quantificação dos dados em relação ao atendimento da norma e nem porcentagem de atendimento em cada categoria. Por isso, sentiu-se a necessidade de quantificá-los a fim de obter uma maior clareza dos resultados, que estão apresentados na Tabela 1.

Para auxiliar na definição dos locais com mais necessidade de intervenção espacial, ordenou-se decrescentemente os itens com mais barreiras físicas a fim de gerar uma hierarquização dos espaços. Após essa classificação, foi realizada uma entrevista com os responsáveis técnicos do CAPS com o objetivo de identificar as barreiras mais relevantes segundo a percepção destes, levando em consideração a experiência dos técnicos no ambiente e a importância de cada categoria para o uso diário da instituição.

A partir disso foi possível criar uma nova hierarquia cruzando os dados da planilha e a opinião dos usuários, de modo a ser atribuído maior ou menor importância às categorias (ver Tabela 2).

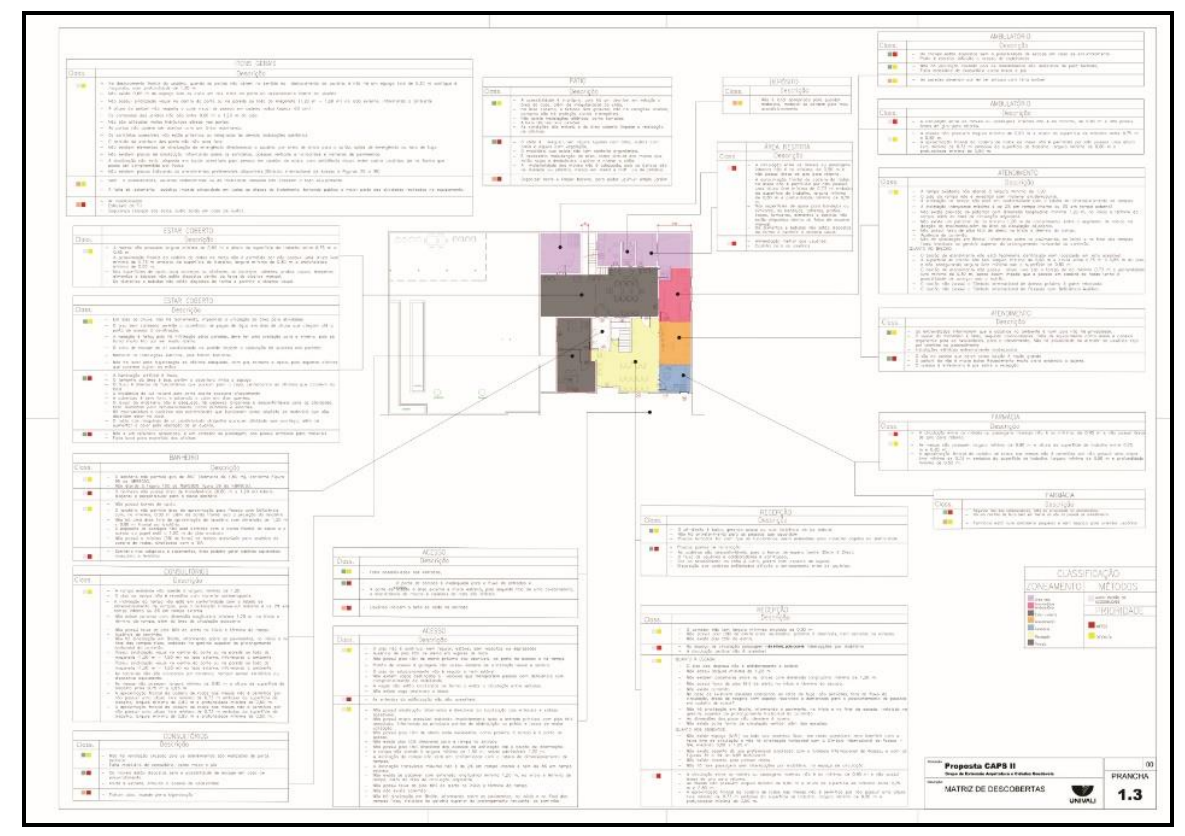

Figura 3 - Matriz de Descobertas -

Fonte: Autores (2018)

Com os dados obtidos com o check list de avaliação e os dados obtidos através das entrevistas com os responsáveis técnicos foi possível elaborar a Matriz de Descobertas. Segundo Rheingantz e Fonseca (2009), este método é uma ferramenta de avaliação pós-ocupação que consiste em transcrever as informações levantadas durante a aplicação dos outros métodos para facilitar a visualização do pesquisador sobre os conflitos existentes nos ambientes.

Para isso, as plantas baixas existentes do edifício foram digitalizadas e organizou-se as descobertas em formato de tabelas, relacionando cada ambiente com as discriminações dos conflitos específicos do local (ver Figura 3). Nesta matriz os conflitos referentes ao espaço foram discriminados segundo várias normas, entre elas a NBR 9050/15.

Tendo concluída a espacialização na Matriz de Descobertas foi possível desenvolver a Matriz de Recomendações que organiza as principais diretrizes projetuais para a solução dos conflitos existentes nos ambientes, aliado às 
recomendações propostas pelos técnicos. Esta ferramenta foi de suma importância para a confecção do estudo preliminar de projeto, pois se configurou um programa de necessidades minucioso com a lista de todas as melhorias das condições espaciais necessárias para o CAPS II (Ver figura 4).

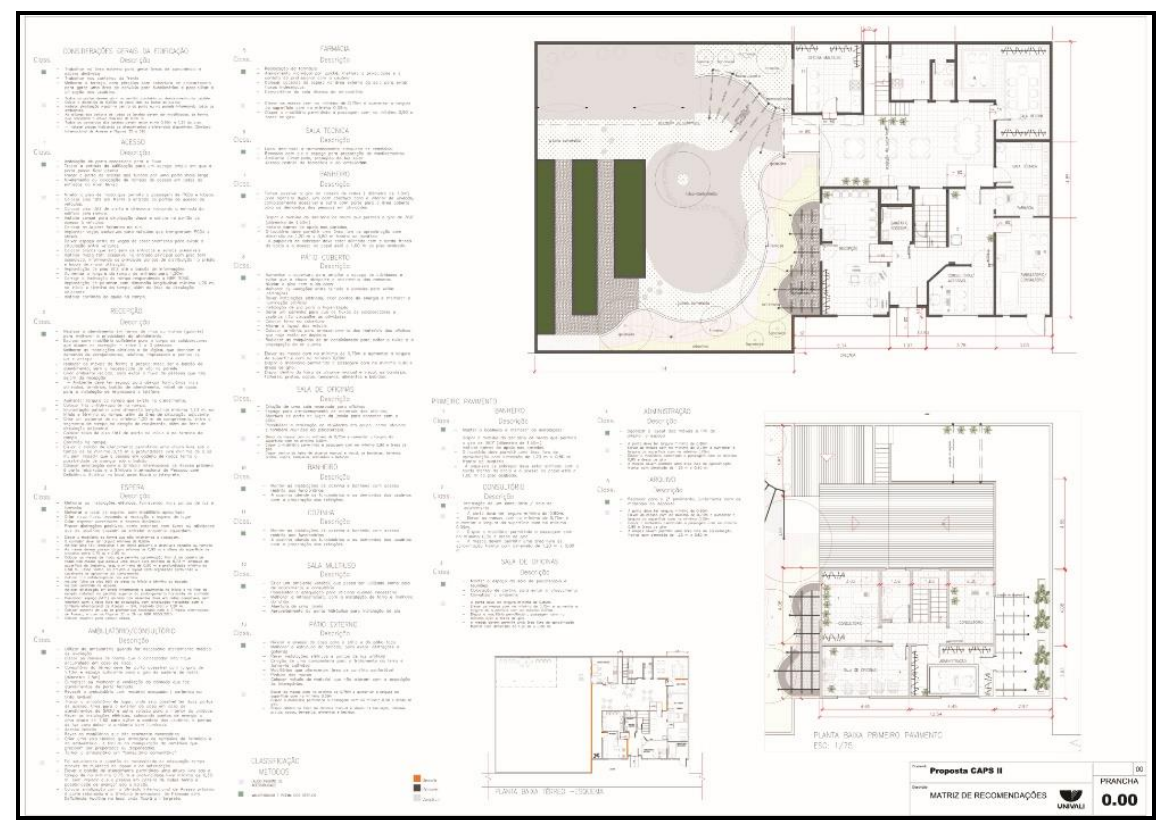

Figura 4 - Matriz de Recomendações -

Fonte: Autoria Própria (2018)

\section{RESULTADOS E DISCUSSÕES}

A aplicação do checklist do Manual de Adaptações de Acessibilidade permitiu quantificar os dados a fim de obter uma melhor visualização gráfica de atendimento à norma para cada categoria que compõe o check list, conforme já mostrado na tabela 2. Por meio desta quantificação, constatouse que 78\% do CAPS II não estava atendendo à NBR 9050/15 (ver Gráfico 1). Em uma primeira hierarquização das categorias por ordem de não atendimento da norma, os assentos ficaram em primeiro lugar, com 100\% dos itens inadequados, já a categoria dos sanitários ficou em último lugar com $70 \%$ dos itens em desacordo com a norma. Porém, conforme já citado, foi realizada uma nova classificação cruzando os dados da planilha com a percepção dos técnicos sobre o uso e a importância de cada categoria e também buscando analisar o que impedia ou dificultava as atividades no local estudado, visando assim definir um grau de urgência nas adequações espaciais que resultou na Tabela 3.

Nos primeiros itens dessa hierarquia, tem-se as rampas, a circulação e as entradas. As rampas, por exemplo, não atendiam $96 \%$ da norma, enquanto os assentos - que nesta hierarquia estavam ao fim da ordem de importância não atendiam $100 \%$. Porém, uma vez que as rampas eram mais imprescindíveis para o uso do espaço, dando acesso aos ambientes em níveis diferentes, elas foram classificadas em primeiro lugar no grau de urgência. Na figura 6 é possível visualizar em vermelho os ambientes da edificação que não poderiam ser acessadas devido a inadequação das rampas. As rampas mal dimensionadas ou inexistentes impossibilitam o acesso à maior parte do 
edifício, enquanto que os assentos dificultam o acesso de quatro ambientes específicos.

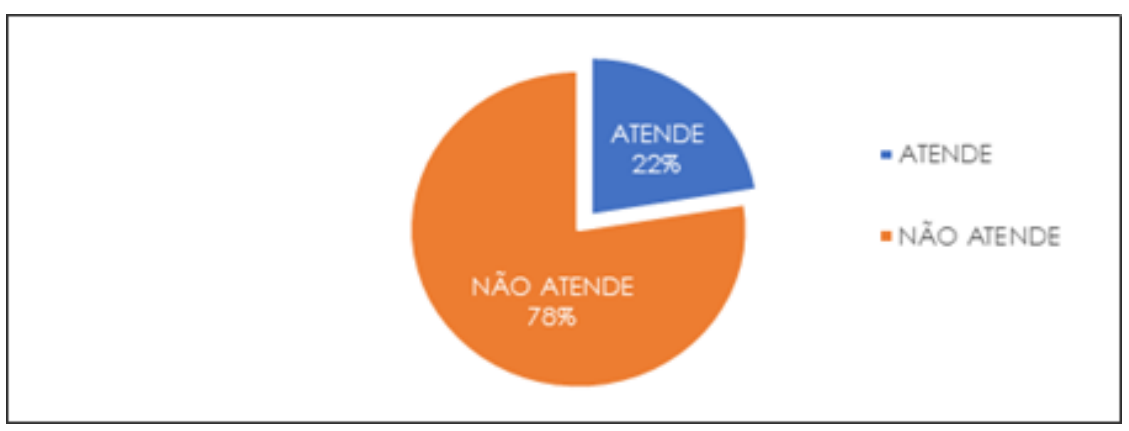

Gráfico 1 - Porcentagem de atendimento e não atendimento à norma Fonte: Autores (2018)

Tabela 3 - Categorias e porcentagem do não atendimento à norma $X$ grau de urgência das adequações espaciais

\begin{tabular}{|c|c|c|}
\hline Grau de urgência & Categoria & Não atende/total de itens \\
\hline 1 & Rampas & $96 \%$ \\
\hline 2 & Circulação & $75 \%$ \\
\hline 3 & Entradas & $78 \%$ \\
\hline 4 & Iluminação e Sinalização & $84 \%$ \\
\hline 5 & Sanitários acessíveis & $70 \%$ \\
\hline 6 & Escadas & $71 \%$ \\
\hline 7 & Interiores & $83 \%$ \\
\hline 10 & Balcões & $33 \%$ \\
\hline 11 & Restaurantes e copas & $100 \%$ \\
\hline
\end{tabular}

Fonte: Autores (2018)

A segunda prioridade foi a circulação, pois a sua inadequação impossibilita o deslocamento contínuo dentro da edificação, fazendo-se necessária a adequação em relação a: ausência de piso tátil de alerta e direcional, espaço insuficiente para à livre passagem sem interrupções e à circulação vertical que se dá apenas pela escada. Em terceiro lugar na hierarquia encontra-se a entrada que, apesar de possuir rampa, não estava na inclinação adequada e sem sinalização podotátil e de apoio. Nos últimos lugares com grau de menor urgência elencou-se a copa e as esquadrias, 
devido sua pouca relevância em relação ao uso da edificação comparado aos outros itens do check list.

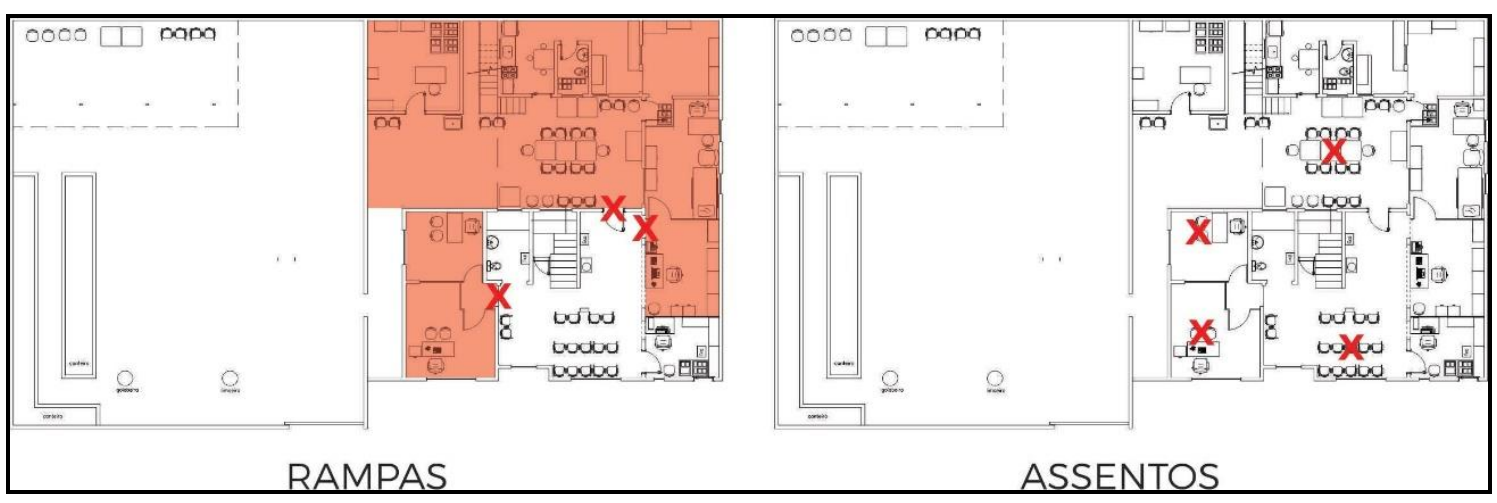

Figura 6 - Comparativo entre importância das rampas e dos assentos Fonte: Autores (2018)

Após essa análise e processamento dos dados, confeccionou-se a Matriz de Descobertas para elucidar as conclusões dos estudos. Essa matriz foi de extrema importância para melhor visualização espacial dos conflitos da edificação. Com esta primeira matriz organizada - como já mostrado na Figura 4 -, gerou-se a Matriz de Recomendações com diretrizes. Na diagramação das recomendações para o projeto de adequação, foi colocado cada ambiente e listado todos os itens a serem levados em consideração para elaborar o projeto. Como exemplo dessas diretrizes propositivas aliadas à norma, está a Figura 7. Na figura à esquerda, propõe-se, na recepção, um alargamento de uma rampa já existente no cômodo de acordo com a NBR 9050/15. Na figura à direita, coloca-se a proposta de implantação de mobiliário que não obstrua a circulação entre toda a edificação.

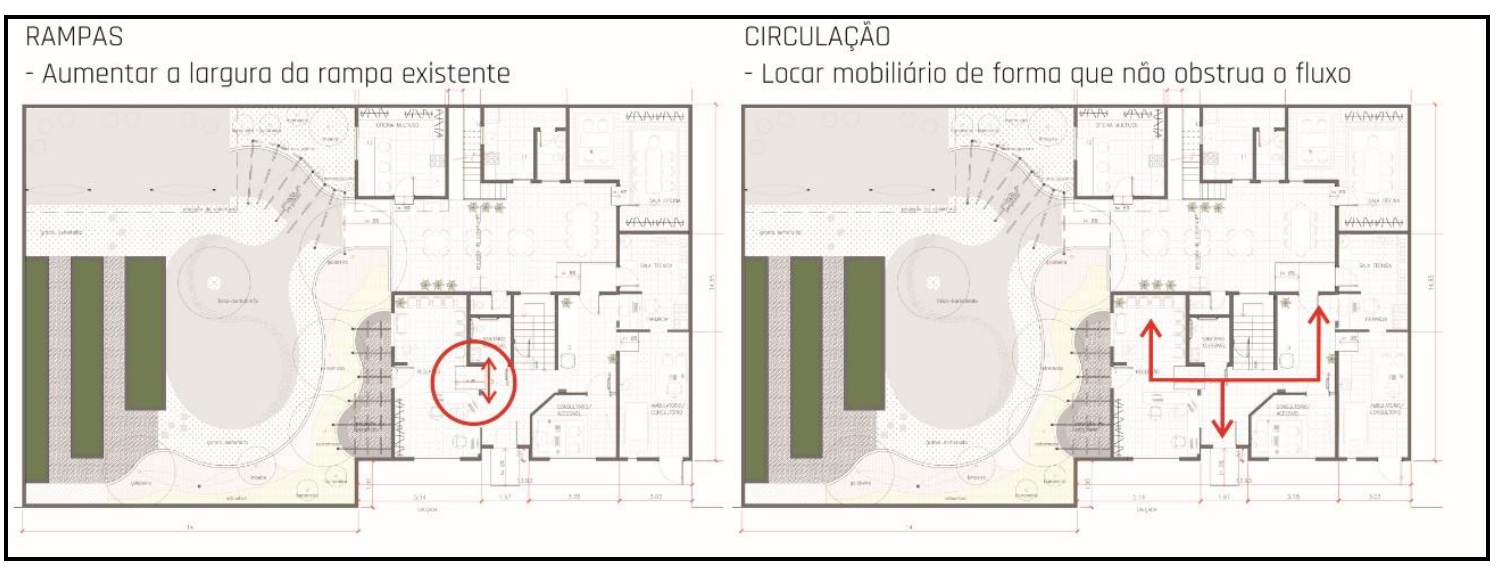

Figura 7 - Recorte da Matriz de Recomendações -

Fonte: Autores(2018)

\section{CONCLUSÕES}

O CAPS é um importante equipamento comunitário que disponibiliza atendimento e acompanhamento clínico para pessoas com sofrimento psicológico de várias magnitudes, promovendo à saúde mental e inclusão social dessa parcela da população. Portanto é essencial que estes espaços sejam adequados ao acesso de todos. 
Infelizmente os resultados desta pesquisa demonstraram no caso do CAPS II de Balneário Camboriú menos de $25 \%$ dos aspectos avaliados estão adequados à NBR9050/2015, o que significa que o espaço não está adequado para atender a diversidade da população. Pode-se concluir que trata-se de um espaço excludente que impossibilita pessoas de receber atendimento de saúde necessário e que lhes é de direito. Este estudo possibilitou a elaboração de diretrizes projetuais de qualificação espacial através de diversas ferramentas.

A planilha do Manual de Adaptações de acessibilidade possibilitou a levantamento dos locais que mais necessitavam de adequação à norma devido sua ampla e detalhada abrangência da NBR 9050/2015, facilitando o entendimento para o aplicador. Embora essa planilha automaticamente se adequasse ao número de pavimentos, de acessos, entre outros, em sua finalização, nada é gerado. Não há processamento automático dos dados, o que requer uma análise, primeiro quantitativa do não atendimento à norma e após qualitativa conforme experiência e conhecimento do local por parte dos técnicos.

As outras duas ferramentas, as matrizes, ajudaram a organizar espacialmente análises e diretrizes. Permitiram aos técnicos uma melhor visualização dos resultados diretamente na planta do CAPS II e facilitaram enormemente a elaboração de proposta para uma futura reforma em busca da adequação à norma.

\section{REFERÊNCIAS}

ASSOCIAÇÃO BRASILEIRA DE NORMAS TÉCNICAS (ABNT). NBR-9050: Informação e documentação - Referências - Elaboração. Rio de Janeiro, 2015.

. NBR 9050: Informação e documentação - Trabalhos Acadêmicos Apresentação. Rio de Janeiro, 2011.

BINS ELY, V. H. M.; DISCHINGER, M.; MATTOS, M. L. Sistemas de Informação Ambiental - Elementos Indispensáveis Para Acessibilidade e Orientabilidade. In: VI Congresso Latino-Americano de Ergonomia e XII Congresso Brasileiro de Ergonomia. Anais do ABERGO, Recife, 2002.

BRASIL. MINISTÉRIO DA SAÚDE. Reforma Psiquiátrica e política de Saúde Mental no Brasil. Disponível em:

<http://bvsms.saude.gov.br/bvs/publicacoes/Relatorio15_anos_Caracas.pdf>. Acesso em: 01 jun. 2019.

COHEN, R.; DUARTE, C.; BRASILEIRO, A. Acessibilidade a museus. Ministério da Cultura / Instituto Brasileiro de Museus. Brasília, DF: MinC/Ibram, 2012.

EMPRESA BRASIL DE COMUNICAÇÃO (EBC). Saúde mental: transtornos atingem cerca de 23 milhões de brasileiros. 2013. Disponível em:

<http://www.ebc.com.br/noticias/saude/2013/05/saude-mental-em-numeroscerca-de-23-milhoes-de-brasileiros-passam-por>. Acesso em: 19 fev. 2019.

RHEINGANTZ, P. A.; FONSECA, J. F. Observando a qualidade do projeto e do lugar. Anais do Simpósio Brasileiro de Qualidade do Projeto no Ambiente Construído. IX Workshop Brasileiro de Gestão do Processo de Projeto na Construção de Edifícios. São Carlos: PPG-AU EESC USP, p. 25 -54, 2009. 
PINTO, C. F. M. Acessibilidade espacial em centros de saúde em Florianópolis/SC: Um estudo de caso. Programa de Pós-Graduação de Arquitetura e Urbanismo. Florianópolis, 2017.

SECRETARIA ESPECIAL DOS DIREITOS DA PESSOA COM DEFICIÊNCIA. Manual de Adaptações de Acessibilidade. 2016. Disponível em:

<http://www.pessoacomdeficiencia.gov.br/app/node/1358>. Acesso em: 11 set. 2018. 